\title{
Genome-wide mapping and estimation of inbreeding depression of semen quality traits in a cattle population
}

\author{
Maja Ferenčaković, ${ }^{*}$ Johann Sölkner, $\dagger^{1}$ Miroslav Kapš, ${ }^{*}$ and Ino Curik* \\ *Department of Animal Science, Faculty of Agriculture, University of Zagreb, Svetosimunska 25, 10000 Zagreb, Croatia \\ †University of Natural Resources and Life Sciences Vienna, Department of Sustainable Agricultural Systems, Division of Livestock Sciences, \\ Gregor Mendel Str. 33, A-1180 Vienna, Austria
}

\section{ABSTRACT}

Inbreeding depression is known to affect quantitative traits such as male fertility and sperm quality, but the genetic basis for these associations is poorly understood. Most studies have been limited to examining how pedigree- or marker-derived genome-wide autozygosity is associated with quantitative phenotypes. In this study, we analyzed possible associations of genetic features of inbreeding depression with percentage of live spermatozoa and total number of spermatozoa in 19,720 ejaculates obtained from 554 Austrian Fleckvieh bulls during routine artificial insemination programs. Genome-wide inbreeding depression was estimated and genomic regions contributing to inbreeding depression were mapped. Inbreeding depression did affect total number of spermatozoa, and such depression was predicted by pedigree-based inbreeding levels and genomewide inbreeding levels based on runs of homozygosity $(\mathrm{ROH})$. Genome-wide inbreeding depression did not seem to affect percentage of live spermatozoa. A model incorporating genetic effects of the bull, environmental factors, and additive genetic and $\mathrm{ROH}$ status effects of individual single-nucleotide polymorphisms revealed genomic regions significantly associated with $\mathrm{ROH}$ status for total number of spermatozoa (4 regions) or percentage of live spermatozoa (5 regions). All but one region contains genes related to spermatogenesis and sperm morphology. These genomic regions contain genes affecting sperm morphogenesis and efficacy. The results highlight that next-generation sequencing may help explain some of the genetic factors contributing to inbreeding depression of sperm quality traits in Fleckvieh bulls.

Key words: inbreeding depression, sperm quality, runs of homozygosity, single nucleotide polymorphism

Received October 17, 2016.

Accepted February 27, 2017.

${ }^{1}$ Corresponding author: johann.soelkner@boku.ac.at

\section{INTRODUCTION}

Inbreeding depression, defined as reduction of the population mean for a quantitative trait such as size, fertility, vigor, yield, and fitness caused by inbreeding, has long been known to occur widely in the plant and animal kingdom, including humans (Kristensen and Sorensen, 2005; Bittles and Black, 2010; Leroy, 2014). Despite its importance, the genetic basis of inbreeding depression, such as the gene pathways or numbers of loci involved, remains unclear. Many studies of animal populations have dealt with such depression simply by performing regression of individual performance on individual pedigree inbreeding coefficients (Kristensen and Sorensen, 2005; Leroy, 2014).

Genome sequencing technologies provide an avenue for more sophisticated approaches to understand the genetic basis of inbreeding depression. Runs of homozygosity (ROH), regions of the genome without heterozygosity in the diploid state (Gibson et al., 2006), have been used to quantify individual inbreeding in humans (McQuillan et al., 2008), cattle (Sölkner et al., 2010; Ferenčaković et al., 2011; Purfield et al., 2012), and pigs (Bosse et al., 2012), and ROH-based results appear to be more accurate than traditional pedigree-based estimates (Curik et al., 2014) and also more accurate than inbreeding coefficients calculated when deriving the genomic relationship matrix based on variance of genotype values (Van Raden, 2008), see Sölkner et al. (2010). These studies have established $\mathrm{ROH}$ inbreeding as an indicator of inbreeding level and they show that this can be calculated with respect to a given reference population, a specific genomic region, or even individual SNP. This opens up several possibilities for exploring the genetic mechanisms of inbreeding depression. In human genetics, the drawback with this approach is the need for extremely large numbers of samples, given that most human populations show low inbreeding levels varying little between individuals (Keller et al., 2012; Howrigan et al., 2016). The higher inbreeding levels and particularly the much higher variability of inbreeding in livestock populations opens up 
the opportunity to analyze local effects of inbreeding at reasonable power with much smaller sample sizes.

Using ROH-derived inbreeding coefficients $\left(\boldsymbol{F}_{\text {ROH }}\right)$ and other estimators of molecular inbreeding, Bjelland et al. (2013) identified inbreeding depression of lactation performance and reproductive traits in Holstein cattle. Those authors concluded that only $F_{R O H}$ can distinguish between identical-by-descent (IBD) markers and identical-by-state markers. Pryce et al. (2014) used $\mathrm{ROH}$ to pinpoint specific genomic regions associated with inbreeding depression of calving interval and milk production. Howard et al. (2015) analyzed milk production and calving interval of Jersey cows in the United States and Australia and found different $\mathrm{ROH}$ signals for the 2 genetically linked populations for dairy traits and only one significant signal for calving interval in the US population.

Inbreeding negatively affects the reproductive performance of male animals. High levels of inbreeding may be a cause of poor semen quality (Wildt et al., 1982; Margulis and Walsh, 2002; Aurich et al., 2003; van Eldik et al., 2006). Using pedigree data and analyses of sperm quality, Maximini et al. (2011) showed that inbreeding depression reduced fertility of Fleckvieh (i.e., dualpurpose Simmental) bulls. In that study, inbreeding affected semen volume, total number of spermatozoa, percentage of live spermatozoa, and sperm motility, all of which serve as quantitative semen quality traits.

Austrian and German Fleckvieh breeding organizations and AI stations, together with research institutions, are very actively pursuing ways of improving male fertility by searching for and acting on mutations causing poor male fertility, either via less viable sperm (Pausch et al., 2014) or embryonic death (Pausch et al., 2015).

To identify genomic regions with effect on inbreeding depression of male sperm quality, we analyzed $\mathrm{ROH}$ in a large set of bulls from 3 Austrian AI stations. Using bovine SNP50 Beadchip technology (Illumina, San Diego, CA), we calculated genome-wide autozygosity from $\mathrm{ROH}$ of different minimum lengths (Ferenčaković et al., 2013) and compared the ability of $\mathrm{ROH}$ and pedigree to predict inbreeding depression of 2 sperm quality traits. We then associated, through autozygosity mapping, both ROH status and genotype of each SNP with sperm quality traits.

\section{MATERIALS AND METHODS}

A total of 1,799 Austrian Fleckvieh bulls were genotyped using the bovine SNP50 Beadchip v1 (Illumina), which contains 54,001 SNP (50k). Those genotypes and pedigree data on 41,090 animals extending back to the 1930s were provided by ZuchtData EDV-Dienstle- istungen $\mathrm{GmbH}$ (Vienna, Austria). The pedigree was checked and recoded using CFC software (Sargolzaei et al., 2006). From the pedigree data, the equivalent complete generations and pedigree inbreeding coefficients for full pedigree $\left(\boldsymbol{F}_{P E D}\right)$ and for 5 generations $\left(\boldsymbol{F}_{\text {PED5 }}\right)$ were calculated using ENDOG v4.8 (Gutiérrez and Goyache, 2005). The equivalent complete generations, defined as the sum of $(1 / 2)^{\mathrm{n}}$, where $\mathrm{n}$ is the number of generations separating the individual from each known ancestor (see the ENDOG v4.8 User's Guide), represents a measure of pedigree quality that indicates distance to the reference population where all individuals are unrelated. The $F_{P E D 5}$ was calculated to quantify recent inbreeding, up to 5 generations back, and provide estimates of recent inbreeding depression.

Sperm quality data were obtained from 3 Austrian AI stations: Gleisdorf station in Styria (7,704 ejaculates, 301 bulls sampled from 2000 to 2010), Hohenzell station in Upper Austria (16,671 ejaculates, 309 bulls sampled from 2000 to 2009), and Wieselburg station in Lower Austria (15,514 ejaculates, 293 bulls sampled from 2000 to 2009). All 3 stations keep bulls in tiestalls and collect semen several times a week, using a dummy or teaser animal and artificial vagina. Staff at the Hohenzell and Wieselburg stations routinely collected ejaculate 2 to 3 times per day from the same bull, whereas workers at the Gleisdorf station collected only 1 ejaculate per day from the same bull. The traits recorded routinely for every ejaculate were semen collector, volume, sperm concentration, percentage of viable spermatozoa, and motility. Motility was not recorded for ejaculates at the Gleisdorf station. Total number of spermatozoa $\left(\times 10^{9}\right)$ in ejaculate was calculated from the volume and concentration of spermatozoa.

Taking into account the SNP density of the bovine 50k SNP chip, we performed quality control and determined $\mathrm{ROH}$ following the settings proposed by Ferenčaković et al. (2013). Only autosomal SNP that were assigned to a chromosome were used in the analysis. We also excluded SNP for which more than $10 \%$ of genotypes were missing and SNP with an Illumina GenCall score $\leq 0.7$ or an Illumina GenTrain score $\leq 0.4$. Bulls with more than $5 \%$ of their genotypes missing were excluded from further analysis. The SNP positions used were from UMD 3.1 (University of Maryland, College Park). The ROH were called if 15 or more consecutive homozygous SNP were present at a density of at least $1 \mathrm{SNP}$ every $100 \mathrm{~kb}$, with gaps of no more than 1,000 kb between them. We defined $4 \mathrm{ROH}$ length categories (in Mb): $[2,4],(4,8],(8,16]$, and $>16$, see Ferenčaković et al. (2013) for the rationale. In different categories, we allowed different number of heterozygous and missing SNP. One heterozygous SNP was allowed in category $>16$, whereas in others we did not allow 
any. In category $(4,8]$, we allowed 1 missing SNP; in category $(8,16]$, we allowed 2 missing SNP; and in category $>16$, we allowed 4 missing SNP. Used thresholds were determined following Ferenčaković et al. (2013). Data sets were then merged to calculate inbreeding coefficients based on $\mathrm{ROH}$ of different minimum lengths

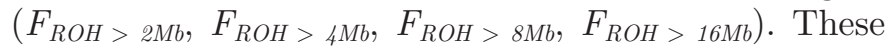
inbreeding coefficients were defined as a total length of the genome covered with $\mathrm{ROH}$ of the certain size (in $\mathrm{Mb}$ ) divided by the total length of genome covered with SNP (McQuillan et al., 2008; Curik et al., 2014). Longer autozygous $\mathrm{ROH}$ are expected to originate from more recent common ancestors because small number of meioses are interrupting long chromosome segments less frequently. In contrast, shorter autozygous $\mathrm{ROH}$ are expected to originate from more remote ancestors because their shorter length is mostly the consequence of a large number of meiosis and recombination events. Thus, by defining $\mathrm{ROH}$ length threshold we are, at the same time, choosing the distance to the base population where all ancestors are assumed not to be related (Howrigan et al., 2011; Curik et al., 2014). Consequently, when the estimation of inbreeding depression is based on $F_{R O H}$, by defining $\mathrm{ROH}$ length threshold we are choosing a set of ancestors contributing to the estimated inbreeding effects. For example, $F_{R O H}>16 \mathrm{Mb}$ inbreeding depression estimates refer to consequences of inbreeding caused by ancestors that are expected within the last 3 generations.

The ROH segments were calculated using SNP \& Variation Suite v7.6.8 for Win64 (Golden Helix, Bozeman, MT) and resulting inbreeding coefficients were derived using SAS scripts we developed for this purpose (2011, version 9.2, SAS Institute Inc., Cary, NC).

Ejaculates were excluded from the analysis if volume was not between 1 and $25 \mathrm{~mL}$, if sperm concentration was not between 0.1 and $3 \times 10^{9} \mathrm{~mL}^{-1}$, or if data were unavailable for some of the sperm quality traits measured. Second and third samplings in the same day were also excluded, as were ejaculates collected from the same bull within less than $4 \mathrm{~d}$. Bulls were excluded from the analysis if fewer than 10 ejaculate samples were available. Bulls that were not found in pedigree were removed as well as bulls without genotype information.

Data for percentage of live spermatozoa showed approximate normal distribution, but data for total number of spermatozoa did not. Therefore, the latter data were transformed using the expression (total number of spermatozoa $\left.{ }^{0.3}-1\right) / 0.3$, determined by the TRANSREG procedure with the BOXCOX option (SAS Institute Inc.; Box and Cox, 1964). Ejaculates for which transformed values fell outside the range of the mean \pm 2.5 standard deviations were excluded. Each ejaculate was checked individually as a possible outlier based on transformed number of spermatozoa and percentage of live spermatozoa using fixed-effects modeling involving bull age, semen collector, month and year of collection, station, and interval of days between 2 ejaculates. Bull age was defined as a categorical variable in months: $<16,16$ to 72 , or $>72$. The period between 2 successive ejaculates was defined as a categorical variable in days: 4 to 7,7 to 9 , or $>9$. Season of collection was defined as a categorical variable in months: February to May, June to September, and October to January. Outliers were detected using the MIXED procedure (SAS Institute Inc.) with the INFLUENCE option. The final data set used in all subsequent analyses contained 19,720 ejaculates from 554 bulls. This data set included only animals where information on pedigree, genotypes, and their semen quality data passed all thresholds described above.

The $F_{R O H}$ or $F_{P E D}$ was used to estimate inbreeding depression using models of the form:

$$
\begin{gathered}
y_{i j k l m n o p}=\mu+\alpha_{i}+\text { age }_{j}+\text { season }_{k}+\text { year }_{l} \\
+ \text { collection_interval }_{m}+\text { semen_collector }{ }_{n} \\
+ \text { station }_{o}+b F_{i j k l m n o p}+\varepsilon_{i j k l m n o p}
\end{gathered}
$$

where $y_{i j k l m n o p}$ is the dependent variable; $\mu$ is the overall mean; $\alpha_{i}$ is the random effect of bull $i$, age ${ }_{j}$ is the fixed effect of age class $j$; $\operatorname{season}_{k}$ is the fixed effect of season class $k$; year r $_{l}$ is the fixed effect of year class $l$; collection_interval $l_{m}$ is the fixed effect of interval in days since the last collection; semen_collector ${ }_{n}$ is the fixed effect of semen collector $n$; station ${ }_{o}$ is the fixed effect of the AI station; $\varepsilon_{i j k l m n o p}$ is the random error; and $b$ is the regression coefficient on inbreeding coefficient $F_{i j k l m n o p}$, which was one of various measures of inbreeding $\left(F_{P E D}\right.$, $F_{P E D 5}, F_{R O H>2 M b}, F_{R O H>4 M b}, F_{R O H>8 M b}$, and $\left.F_{R O H>16 M b}\right)$. Separate models were employed for each measure of inbreeding. All fixed effects were selected based on known models from literature and on the available data, and their significances were tested.

The bull effect $\alpha_{i}$ was assumed to show the normal distribution described by $N\left(0, \mathbf{G} \sigma_{S}^{2}\right)$, where $\mathbf{G}$ is the realized genomic relationship matrix calculated using IBD algorithms as described by Oliehoek et al. (2006), calculated using JMP Genomics 5.0 (SAS Institute Inc.), and $\sigma_{S}^{2}$ is bull variance. Data were fitted to models using the MIXED procedure and maximum likelihood method implemented in SAS 9.3 (SAS Institute Inc.). The inbreeding measures affecting either percentage of live spermatozoa or total number of spermatozoa were compared with the Akaike information criteria (AIC) of the models (Burnham and Anderson, 2007). 
In this approach, $\Delta \mathrm{AIC}<3$ indicate no significant difference between models, $\Delta$ AIC 3 to 7 indicate considerably less support, and $\triangle \mathrm{AIC}>7$ indicate that the model is not very likely.

Modeling to map genomic regions was carried out as described above, except that $b F_{i j k l m n o p}$ was replaced by $b_{1} S N P_{i j k l m n o p}$ and $b_{2} F_{R O H}>2 M b i j k l m n o p$, where $b_{1}$ is the regression coefficient for the additive effect of $S N P_{i j k l m n o p}$, and $b_{2}$ is the regression coefficient on $F_{R O H}>2 M b$ ijklmnop. At each SNP position, $S N P_{i j k l m n o p}$ was coded as 0 for homozygous, 1 for heterozygous, or 2 for alternative homozygous. $R O H_{i j k l m n o p}$ was coded as 1 if the SNP lay within the ROH, 0 if it did not (Pryce et al., 2014). Data were analyzed using restricted maximum likelihood within the MIXED procedure. The model was applied to every autosomal SNP in the final data set $(42,817$ runs). After editing, the data set contained records of only 554 bulls. Instead of the typical additive relationship matrix, the realized IBD matrix only for those 554 bulls was used. Unfortunately, numerical separation of permanent environment effects from polygenic ones was not possible. Thus, the bull effect actually contains both effects. However, with this it was possible to define a total variability between bulls which serves here only to adjust variability due to the ROH status.

The $P$-values were adjusted using the multiple-testing correction described by Gao et al. (2008). This "simpleM" procedure uses composite linkage disequilibrium to create a correlation matrix of SNP and calculate the effective number of independent tests $\left(M_{e f f}\right.$; Cheverud, 2001), in this case the effective number of independent SNP. This value was then used in the Bonferroni correction formula (Holm, 1979).

The SNP with significant effects on either percent of live spermatozoa or total number of spermatozoa, as well as annotated genes lying $\pm 1 \mathrm{Mb}$ from those SNP were analyzed using Ensembl BioMart MartView (Aken et al., 2016). Only genes with a known function described in UniProt (http://www.uniprot.org), GeneCards (The Human Gene Database v4.3.4, Build 27; http://www.genecards.org), or both, were investigated.

\section{RESULTS AND DISCUSSION}

\section{Estimation of Genome-Wide Inbreeding Depression}

Overall statistics on phenotypes, pedigree completeness, pedigree inbreeding coefficients, and $\mathrm{ROH}$ inbreeding coefficients are presented in Table 1. As expected, the highest values of inbreeding were estimated using $F_{R O H}>2 M b$ because short ROH segments were allowed (Ferenčaković et al., 2011). Please note that the lower limit of $2 \mathrm{Mb}$ is below the limit of $4 \mathrm{Mb}$ advised by Ferenčaković et al. (2013) for bovine 50k SNP chip data. In that study, most of the false positive $\mathrm{ROH}$ segments from 50k data were in the range of 1 to $2 \mathrm{Mb}$. For the current inbreeding depression study, we wanted to cover effects derived not only from very recent inbreeding, at the risk of a small number of false positives. Significant inbreeding depression of the total number of spermatozoa (transformed values) was detected using the pedigree inbreeding coefficient $\left(F_{P E D}\right)$ and inbreeding coefficient derived from $\mathrm{ROH}$ segments $>2 \mathrm{Mb}\left(F_{R O H}>2 M b ; P<0.05\right.$, Table 2$)$. Similar results were obtained using $F_{P E D}$ in a previous analysis of a subset of the data analyzed here (Maximini et al., 2011). Based on $\triangle \mathrm{AIC}, F_{P E D}$ was found to be the best measure of inbreeding in estimating inbreeding depression for total number of sperm. The $F_{R O H}>2 M b$ had $\triangle$ AIC 3.9, suggesting it is still adequate for detecting inbreeding depression. The $F_{R O H}$ based on $\mathrm{ROH}$ segments $>4 \mathrm{Mb}$ or longer and the $F_{P E D 5}$ showed poorer ability to explain the effects of inbreeding on the total number of spermatozoa in our data set.

No coefficient gave significant regression coefficients for inbreeding depression of the percent of viable spermatozoa (Table 2). In contrast, Maximini et al. (2011)

Table 1. Descriptive statistics for phenotypes, pedigree completeness, and the various inbreeding coefficients ${ }^{1}$

\begin{tabular}{lcccc}
\hline Item & Mean & SD & Minimum & Maximum \\
\hline Total no. of spermatozoa $\left(10^{9}\right)$ & 7.852 & 3.624 & 1.103 & 22.554 \\
Total no. of spermatozoa $($ transformed) & 2.712 & 0.874 & 0.089 & 5.158 \\
Live spermatozoa (\%) & 66.4 & 5.8 & 35.0 & 90.0 \\
Complete generations equivalent & 6.824 & 0.628 & 4.577 & 8.319 \\
$F_{P E D}$ & 0.0127 & 0.0111 & 0.0000 & 0.0753 \\
$F_{P E D 5}$ & 0.0096 & 0.0103 & 0.0000 & 0.0703 \\
$F_{R O H}>2 M b$ & 0.0471 & 0.0164 & 0.0105 & 0.1455 \\
$F_{R O H}>4 M b$ & 0.0273 & 0.0152 & 0.0024 & 0.1213 \\
$F_{R O H>8 M b}$ & 0.0142 & 0.0132 & 0.0000 & 0.1020 \\
$F_{R O H>16 M b}$ & 0.0064 & 0.0093 & 0.0000 & 0.0713 \\
\hline$F_{P E D}$ and
\end{tabular}

${ }^{1} F_{P E D}$ and $F_{P E D 5}=$ pedigree inbreeding coefficients based on all and 5 generations, respectively; $F_{R O H}>2 M b$,

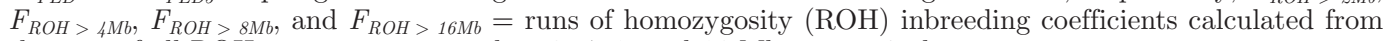
the sum of all ROH segments greater than $2,4,8$, and $16 \mathrm{Mb}$, respectively. 
Table 2. Effects of a $10 \%$ increase in inbreeding $(F)$ on the percentage of live spermatozoa and total number of spermatozoa

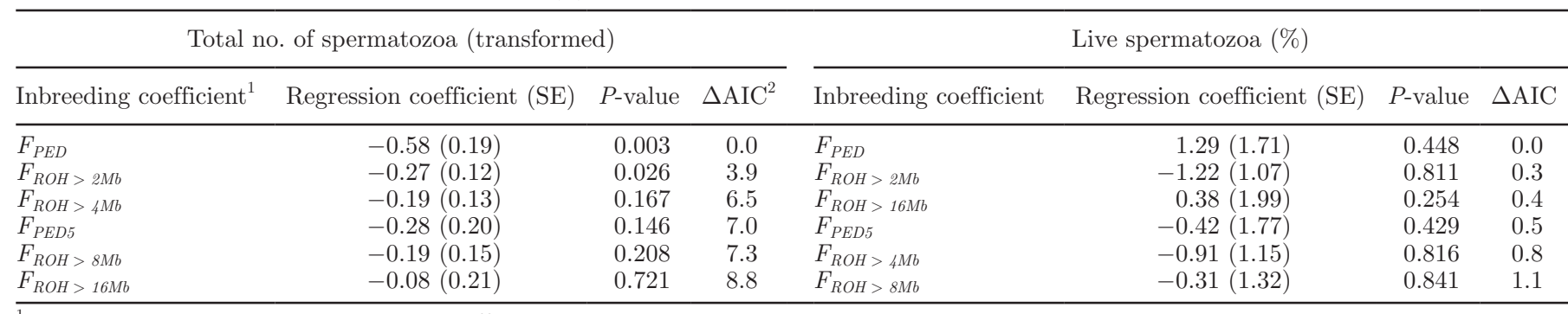

${ }^{1} F_{P E D}$ and $F_{P E D 5}=$ pedigree inbreeding coefficients based on all and 5 generations, respectively; $F_{R O H}>2 M b, F_{R O H}>4 M b, F_{R O H}>8 M b$, and $F_{R O H}>16 M b$ $=$ runs of homozygosity $(\mathrm{ROH})$ inbreeding coefficients calculated from the sum of all ROH segments greater than 2, 4, 8, and $16 \mathrm{Mb}$, respectively.

${ }^{2} \mathrm{AIC}=$ Akaike information criterion

reported significant depression of this trait analyzing separately semen quality data from the AI station Wieselburg (398 bulls, collection period 2000-2006) and Hohenzell (317 bulls, collection period 2000-2004) and using model with different fixed effects.

Although $F_{R O H}$ has already been used to confirm inbreeding depression of reproductive traits in cows (Bjelland et al., 2013; Kim et al., 2013, 2015; Pryce et al., 2014) and pigs (Saura et al., 2015), the present report is the first to our knowledge that applies the same tool to sperm quality in any species. Numerous studies have documented that inbreeding depression (measured using $\left.F_{P E D}\right)$ causes sperm quality defects in various species, including wild mammals (Shivaji et al., 1998; Asa et al., 2007; Ruiz-Lopez et al., 2010), domestic cats (Pukazhenthi et al., 2006), and horses (van Eldik et al., 2006). Gage et al. (2006) and Fitzpatrick and Evans (2009) concluded that sperm quality is susceptible to inbreeding depression because spermatogenesis relies on highly regulated developmental genes, and the appearance of deleterious alleles or loss in heterozygosity can directly affect sperm quality. Maximini et al. (2011) described a low negative correlation between inbreeding and sperm quality in Fleckvieh bulls, whereas Dorado et al. (2015) suggested that high inbreeding levels have a moderate negative effect on bull semen quality, with an increased percentage of highly active but nonprogressive spermatozoa.

\section{Mapping of Genomic Regions Associated with Inbreeding Depression}

Analysis of genomic regions associated with inbreeding depression was performed for every autosomal SNP. We defined the number of independent SNP for every chromosome following the procedure by Gao et al. (2008). This number varied between 150 and 260 depending on the number of SNP on a chromosome and the levels of linkage disequilibrium (LD). The number of independent SNP was then used in the Bonferroni cor- rection formula (Holm, 1979) for defining significance thresholds. Obtained $-\log (P)$ value varied across chromosomes from 3.48 to 3.72 for significant $(P<0.05)$, and from 4.18 to 4.42 for highly significant $(P<0.01)$ SNP. The model included the additive effect of the SNP at a given position as well as its $\mathrm{ROH}$ status, giving rise to 22 signals on chromosomes $10,17,20$, and 27 with significant negative effects of ROH status on total number of spermatozoa (21 significant and 1 highly significant). The number of individuals with significant SNP being in $\mathrm{ROH}$ state ranged from 13 to $41(2.3-7.4 \%$ of the sample) The corresponding analysis of inbreeding depression of the percent of live spermatozoa identified 29 significant signals on chromosomes $1,6,10,14$, and 20 (18 significant and 11 highly significant). One region on chromosome 6 had a very high $\mathrm{ROH}$ frequency of $32.3 \%$ with $\mathrm{ROH}$ status effects of around $-2.1 \%$ and 3 regions in which $\mathrm{ROH}$ status was rare $(0.9-1.3 \%)$ but effects were very strong $(-4.3$ to $-7.9 \%)$. Manhattan plots with $-\log _{10} P$-values of $\mathrm{ROH}$ and additive signals for both traits are provided in Supplemental Figures S1 and S2 (https://doi.org/10.3168/jds.2016-12164). Annotated genes within $\pm 1 \mathrm{Mb}$ from the signals associated with $\mathrm{ROH}$ status and with function in the male reproductive system are graphically presented in Figure 1. Lists of all genes and their functions in those regions are presented in Supplemental Tables S1 and S2 (https://doi.org/10.3168/jds.2016-12164). Among 31 genes linked to inbreeding depression of total number of spermatozoa in our data, 4 have previously been linked to spermatogenesis and male fertility. The ribosomal protein L10-like (RPL10L) gene on chromosome 10 plays a role in compensating for the inactivated $\mathrm{X}$-linked gene during spermatogenesis (http://www. uniprot.org; Uechi et al., 2002), and it has been linked to severe spermatogenic failure (Ansari-Pour et al., 2016). The gene solute carrier family 25 (mitochondrial carrier; adenine nucleotide translocator), member 31 [also known as sperm flagellar energy carrier protein (SLC25A31)] on chromosome 17 catalyzes the exchange 
of cytoplasmic ADP with mitochondrial ATP across the mitochondrial inner membrane. It mediates energy generation and consumption in the distal flagellum, possibly by shuttling nucleotides among the pathways of flagellar glycolysis, protein phosphorylation, and motility (http://www.genecards.org; Palmieri, 2013). The only significant signal with a positive effect in the autozygous state was on chromosome 20, close to the gene cadherin 18, type $2(C D H 18)$ encoding type II classical cadherin from the cadherin superfamily of integral membrane proteins that mediate calciumdependent cell-cell adhesion. This gene significantly influences motility of spermatozoa (Pacheco et al., 2011). The signal on chromosome 27 was in the vicinity of the potassium channel, subfamily $\mathrm{U}$, member 1 (KCNU1) gene. It encodes a testis-specific potassium channel that mediates export of $\mathrm{K}+$ and thereby the primary $\mathrm{K}+$ current in spermatozoa critical for fertility. This channel also plays an important role in sperm osmoregulation to maintain normal morphology and motility in the presence of osmotic challenges, such as after mixing of sperm and seminal fluid and entry into the vagina (http://www.uniprot.org; Schreiber et al., 1998).

Analysis of genomic regions associated with inbreeding depression of live spermatozoa identified 53 genes. Analysis of functional annotations of the genes identified 9 strong candidates associated with male fertility, located on chromosomes 1, 6, 10, and 14. No obvious candidate was observed on chromosome 20 (Supplemental Tables S1 and S2; https://doi.org/10.3168/ jds.2016-12164). The genomic regions associated with percentage of live spermatozoa do not overlap with regions associated with total number of spermatozoa (Figure 1). Four significant depression-associated signals were found inside the spermatogenesis associated 16 (SPATA16) gene on chromosome 1; an autosomal recessive SPATA16 variant is associated with male infertility in homozygous members of a consanguineous family of humans (Dam et al., 2007). This type of infertility is caused by spermatogenesis defects, resulting in malformation or even absence of the acrosome. Spermatozoa in affected animals can also show abnormal nuclear shape and mitochondrial arrangement (Dam et al., 2007). SPATA\%, another gene from the same family as SPATA16, has been linked to semen volume and total number of sperm in cattle in a genome-wide association study (Hering et al., 2014).

Signals on chromosome 1 were near the genes glutathione peroxidase 5 (GPX5) and epididymis secretory sperm binding protein Li 75p. The protein encoded by GPX 5 has been proposed to play a role in protecting the spermatozoa membrane from lipid peroxidation during oxidative stress, as well as potentially preventing a pre- mature acrosome reaction (http://www.genecards.org; Hall et al., 1998). Levels of GPX5 in seminal plasma may serve as markers of boar sperm quality (Shojaei Saadi et al., 2013).

Another significant negative signal was found in the vicinity of spermatogenesis associated 18 (SPATA18) gene, which encodes a so-called "mitochondrion-eating protein." This protein mediates the repair or degradation of unhealthy mitochondria in response to damage. The gene is expressed at higher levels in testis than in other tissues, and the protein is found in sperm flagellum (http://www.genecards.org; Bornstein et al., 2011).

Signals were found next to 5 genes with functions suggesting connection with male fertility. The gene testis development protein NYD-SP5 (IQCH) seems to play a regulatory role in spermatogenesis (http:// www.genecards.org; Yin et al., 2005). The gene protein inhibitor of activated STAT, 1 (PIAS1) encodes a nuclear receptor transcriptional co-regulator in testis and plays a role in androgen receptor-mediated initiation and maintenance of spermatogenesis (Vernocchi et al., 2014). The protein encoded by Fem-1-like death receptor-binding protein alpha $(F E M 1 B)$ participates in the generation and organization of the branching structure of the prostate gland, as well as in the maturation of epithelial cells involved in prostate gland development (http://www.uniprot.org; Wang et al., 2008). The gene sperm equatorial segment protein 1 (SPESP1) is highly expressed in testis, where it localizes to the acrosome during postmeiotic stages of spermatogenesis (appearance of round, elongated spermatids and in ejaculated spermatozoa) (http://www.genecards.org; Wolkowicz et al., 2008). The gene is involved in the sperm acrosome reaction and in the fusion of sperm with the egg plasma membrane in cattle (http://www.uniprot.org; Soggiu et al., 2013). The gene NADPH oxidase, EF-hand calcium binding domain 5 (NOX5) is expressed predominantly in the testis and in lymphocyte-rich areas of spleen and lymph nodes. It encodes a calcium-dependent NADPH oxidase that generates superoxide; it also functions as a calcium-dependent proton channel that may regulate redox-dependent processes in lymphocytes and spermatozoa in humans and equines (Sabeur and Ball, 2007; Musset et al., 2012).

Among 18 genes that our model identified on chromosome 14, only one has an established connection with male fertility. The gene testis-specific Y-encoded-like protein 5 protein (TSPYL5) is overexpressed in testis and appears, based on homology with other genes, to be involved in the cellular response to gamma radiation, regulation of cell proliferation, and positive regulation of protein kinase $\mathrm{B}$, protein ubiquitination, and male idiopathic infertility (http://www.uniprot.org; Javaher et al., 2012). 
The sperm quality parameters checked in the routine of AI stations, as used in this study, only give a rough indication of the ability of sperm to successfully penetrate the ova of a cow in heat and cause pregnancy. Working with Fleckvieh fertility data, Pausch et al. (2014) located a mutation of the transmembrane

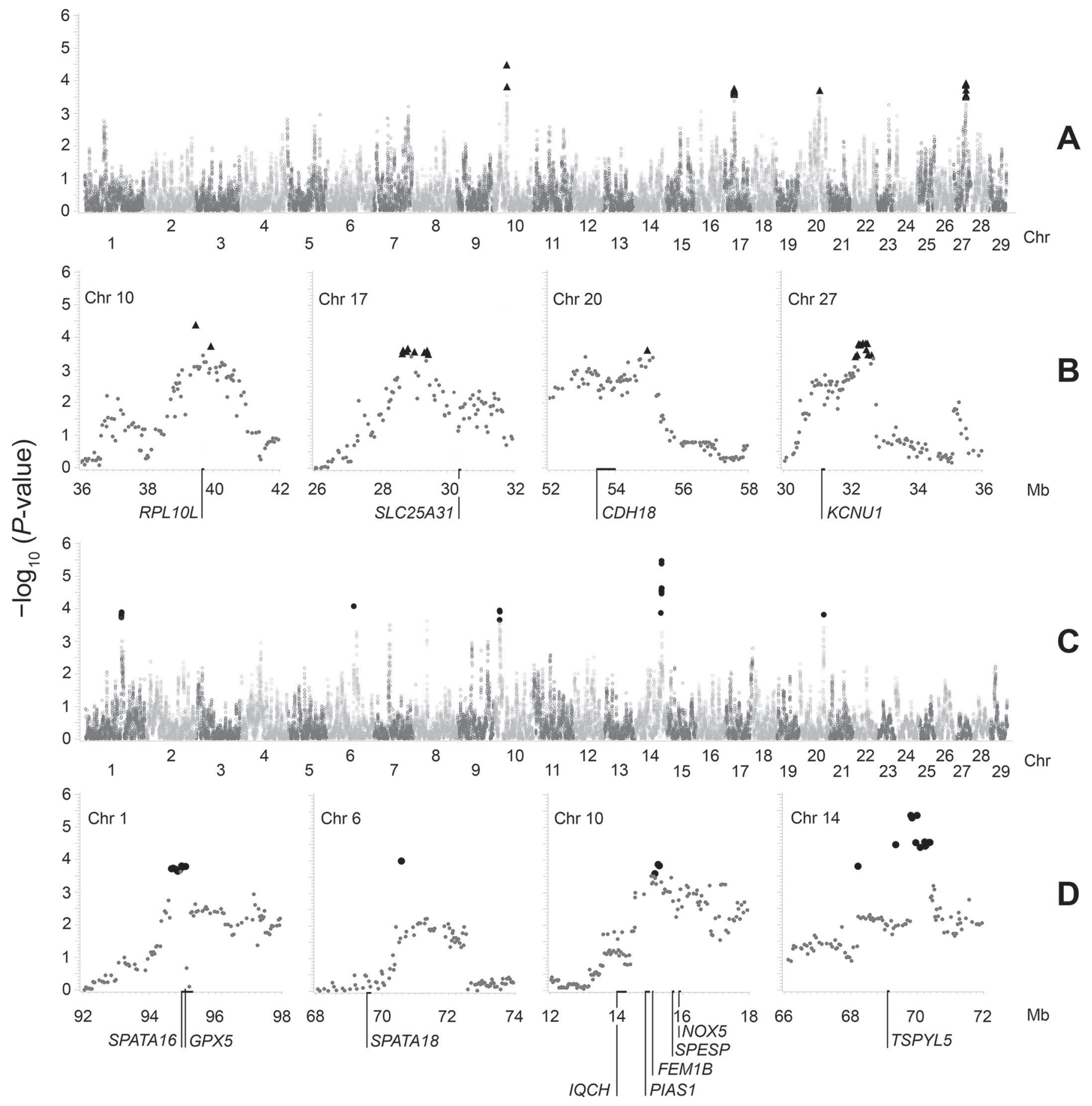

Figure 1. Significance of estimated runs of homozygosity effects for male fertility traits according to genome location. Significance of estimated effects for the total number of spermatozoa and percentage of live spermatozoa are illustrated in a Manhattan plot in panels A and C for whole genome, whereas significant estimates with location of suspected genes associated with function in the male reproductive system are presented in panels B and D, respectively. Gene names are according to Ensembl BioMart MartView (Aken et al., 2016). Chr = chromosome; $\mathrm{Mb}=$ megabase. 
protein coding gene TMEM95 on bovine chromosome 19 with a strong negative effect on male fertility, based on poor nonreturn rate in inseminated female animals. The mutation was located via genome-wide association analysis, autozygosity mapping of the most significant region and sequence analysis. Only bulls homozygous for the mutation showed poor fertility. The sperm quality traits as used here were not different from those of much more fertile bulls. Immunohistochemical analysis showed that TMEM95 is located at the surface of spermatozoa of fertile animals, whereas it is absent in spermatozoa of subfertile animals. This mutation is therefore a major contributor to inbreeding depression for male fertility in the Fleckvieh breed. It was not identified with the method presented here because the sperm quality was apparently normal (i.e., idiopathic).

\section{CONCLUSIONS}

The results obtained in this study indicate the suitability of analyzing $\mathrm{ROH}$ patterns to dissect genetic factors and mechanisms behind inbreeding depression in livestock populations. This approach appears effective both for estimating genome-wide levels of inbreeding and for mapping inbreeding effects at the level of individual SNP. Further investigation of these regions based on resequencing data should help clarify the molecular mechanisms of inbreeding depression of male fertility. Much attention is currently given, with great success (Sonstegard et al., 2013; Pausch et al., 2015), to finding heterozygous carriers of alleles causing embryonic death due to recessive lethal gene action. The approach presented here tries to address low fertility of bulls where alleles in homozygous state affect fertility during spermatogenesis or through malformation of sperm. This approach may be as successful and useful as the one described above.

\section{ACKNOWLEDGMENTS}

The authors declare that there are no competing interests. JS, IC, and MF conceived the study, and MK made key decisions about statistical analysis. MF performed the bulk of the analyses with the support of all other authors. MF drafted the manuscript, and all authors contributed to the final version of the manuscript. The authors gratefully acknowledge the directors and staff of the 3 artificial insemination stations involved (Gleisdorf, Hohenzell, and Wieselburg) for provision of sperm quality data. Lina Grill (formerly Maximini) and Birgit Fuerst-Waltl (both from BOKU, Vienna, Austria) provided us with the data of 2 of these stations used in a previous study. We thank ZuchtData GmbH for providing genotype and Pedigree data. Many thanks to Mario Matković from Croatian Livestock Reproduction Centre (CRSH d.o.o.) for valuable information about bull reproductive physiology. This research was supported by a bilateral collaborative project involving the Croatian Ministry of Science, Education and Sports, and the Austrian Agency for International Cooperation in Education and Research (OeAD GmbH; "Runs of homozygosity: Detecting selection in livestock populations"). Finally, we acknowledge the editor and the anonymous reviewers for their valuable comments and suggestions. Their expertise significantly contributed to the quality of the manuscript.

\section{REFERENCES}

Aken, B. L., S. Ayling, D. Barrell, L. Clarke, V. Curwen, S. Fairley, J. Fernandez Banet, K. Billis, C. García Girón, T. Hourlier, K. Howe, A. Kähäri, F. Kokocinski, F. J. Martin, D. N. Murphy, R. Nag, M. Ruffier, M. Schuster, Y. A. Tang, J.-H. Vogel, S. White, A. Zadissa, P. Flicek, and S. M. J. Searle. 2016. The Ensembl gene annotation system. Database (Oxford) 2016:baw093. https://doi. org/10.1093/database/baw093.

Ansari-Pour, N., Z. Razaghi-Moghadam, F. Barneh, and M. Jafari 2016. Testis-specific Y-centric protein-protein interaction network provides clues to the etiology of severe spermatogenic failure. J. Proteome Res. 15:1011-1022. https://doi.org/10.1021/acs. jproteome.5b01080.

Asa, C., P. Miller, M. Agnew, J. A. R. Rebolledo, S. L. Lindsey, M. Callahan, and K. Bauman. 2007. Relationship of inbreeding with sperm quality and reproductive success in Mexican gray wolves. Anim. Conserv. 10:326-331. https://doi.org/10.1111/j.14691795.2007.00116.x.

Aurich, C., R. Achmann, and J. E. Aurich. 2003. Semen parameters and level of microsatellite heterozygosity in Noriker draught horse stallions. Theriogenology 60:371-378. https://doi.org/10.1016/ S0093-691X(03)00005-0.

Bittles, A. H., and M. L. Black. 2010. Consanguinity, human evolution, and complex diseases. Proc. Natl. Acad. Sci. USA 107: https://doi.org/10.1073/pnas.0906079106.

Bjelland, D. W., K. A. Weigel, N. Vukasinovic, and J. D. Nkrumah. 2013. Evaluation of inbreeding depression in Holstein cattle using whole-genome SNP markers and alternative measures of genomic inbreeding. J. Dairy Sci. 96:4697-4706. https://doi.org/10.3168/ jds.2012-6435.

Bornstein, C., R. Brosh, A. Molchadsky, S. Madar, I. Kogan-Sakin, I. Goldstein, D. Chakravarti, E. R. Flores, N. Goldfinger, R. Sarig, and V. Rotter. 2011. SPATA18, a spermatogenesis-associated gene, is a novel transcriptional target of p53 and p63. Mol. Cell. Biol. 31:1679-1689. https://doi.org/10.1128/MCB.01072-10.

Bosse, M., H. J. Megens, O. Madsen, Y. Paudel, L. A. F. Frantz, L. B. Schook, R. P. M. A. Crooijmans, and M. A. M. Groenen. 2012. Regions of homozygosity in the porcine genome: Consequence of demography and the recombination landscape. PLoS Genet. 8:e1003100. https://doi.org/10.1371/journal.pgen.1003100.

Box, G. E. P., and D. R. Cox. 1964. An analysis of transformations. J. R. Stat. Soc. Ser. B (Methodological) 211-252. https://doi. org $/ 10.2307 / 2287791$.

Burnham, K. P., and D. R. Anderson. 2007. Model Selection and Multimodel Inference: A Practical Information-Theoretic Approach. Springer New York, New York, NY.

Cheverud, J. M. 2001. A simple correction for multiple comparisons in interval mapping genome scans. Heredity (Edinb.) 87:52-58. https://doi.org/10.1046/j.1365-2540.2001.00901.x. 
Curik, I., M. Ferenčaković, and J. Sölkner. 2014. Inbreeding and runs of homozygosity: A possible solution to an old problem. Livest. Sci. 166: https://doi.org/10.1016/j.livsci.2014.05.034.

Dam, A. H. D. M., I. Koscinski, J. A. M. Kremer, C. Moutou, A.S. Jaeger, A. R. Oudakker, H. Tournaye, N. Charlet, C. LagierTourenne, H. van Bokhoven, and S. Viville. 2007. Homozygous mutation in SPATA16 is associated with male infertility in human globozoospermia. Am. J. Hum. Genet. 81:813-820. https://doi. org/10.1086/521314.

Dorado, J., R. M. Cid, A. Molina, M. Hidalgo, J. Ariza, M. MorenoMillán, and S. Demyda-Peyrás. 2015. Effect of inbreeding depression on bull sperm quality and field fertility. Reprod. Fertil. Dev. https://doi.org/10.1071/RD15324.

Ferencakovic, M., E. Hamzic, B. Gredler, I. Curik, and J. Sölkner. 2011. Runs of homozygosity reveal genomewide autozygosity in the Austrian Fleckvieh cattle. Agric. Conspec. Sci. 76.

Ferenčaković, M., J. Sölkner, and I. Curik. 2013. Estimating autozygosity from high-throughput information: Effect of SNP density and genotyping errors. Genet. Sel. Evol. 45:42. https://doi. org/10.1186/1297-9686-45-42.

Fitzpatrick, J. L., and J. P. Evans. 2009. Reduced heterozygosity impairs sperm quality in endangered mammals. Biol. Lett. 5:320323. https://doi.org/10.1098/rsbl.2008.0734

Gage, M. J. G., A. K. Surridge, J. L. Tomkins, E. Green, L. Wiskin, D. J. Bell, and G. M. Hewitt. 2006. Reduced heterozygosity depresses sperm quality in wild rabbits, Oryctolagus cuniculus. Curr. Biol. 16:612-617. https://doi.org/10.1016/j.cub.2006.02.059.

Gao, X., J. Starmer, and E. R. Martin. 2008. A multiple testing correction method for genetic association studies using correlated single nucleotide polymorphisms. Genet. Epidemiol. 32:361-369. https:// doi.org/10.1002/gepi.20310,

Gibson, J., N. E. Morton, and A. Collins. 2006. Extended tracts of homozygosity in outbred human populations. Hum. Mol. Genet. 15:789-795. https://doi.org/10.1093/hmg/ddi493.

Gutiérrez, J. P., and F. Goyache. 2005. A note on ENDOG: A computer program for analysing pedigree information. J. Anim. Breed. Genet. 122:172-176. https://doi.org/10.1111/j.14390388.2005.00512.x.

Hall, L., K. Williams, A. C. Perry, J. Frayne, and J. A. Jury. 1998. The majority of human glutathione peroxidase type 5 (GPX5) transcripts are incorrectly spliced: Implications for the role of GPX5 in the male reproductive tract. Biochem. J. 333:5-9. https://doi. org $/ 10.1042 / \mathrm{bj} 3330005$.

Hering, D. M., K. Olenski, and S. Kaminski. 2014. Genome-wide association study for poor sperm motility in Holstein-Friesian bulls. Anim. Reprod. Sci. 146:89-97. https://doi.org/10.1016/j. anireprosci.2014.01.012.

Holm, S. 1979. A simple sequentially rejective multiple test procedure. Scand. J. Stat. 6:65-70. https://doi.org/10.2307/4615733.

Howard, J. T., M. Haile-Mariam, J. E. Pryce, and C. Maltecca. 2015. Investigation of regions impacting inbreeding depression and their association with the additive genetic effect for United States and Australia Jersey dairy cattle. BMC Genomics 16:813. https://doi. org/10.1186/s12864-015-2001-7.

Howrigan, D. P., M. Simonson, G. Davies, S. E. Harris, A. Tenesa, J. M. Starr, D. C. Liewald, I. J. Deary, A. McRae, M. J. Wright, G. W. Montgomery, N. Hansell, N. G. Martin, A. Payton, M. Horan, W. E. Ollier, A. Abdellaoui, D. I. Boomsma, P. DeRosse, E. E. M. Knowles, D. C. Glahn, S. Djurovic, I. Melle, O. A. Andreassen, A. Christoforou, V. M. Steen, S. L. Hellard, K. Sundet, I. Reinvang, T. Espeseth, A. J. Lundervold, I. Giegling, B. Konte, A. M. Hartmann, D. Rujescu, P. Roussos, S. Giakoumaki, K. E. Burdick, P. Bitsios, G. Donohoe, R. P. Corley, P. M. Visscher, N. Pendleton, A. K. Malhotra, B. M. Neale, T. Lencz, and M. C. Keller. 2016. Genome-wide autozygosity is associated with lower general cognitive ability. Mol. Psychiatry 21:837-843. https://doi.org/10.1038/ mp.2015.120.

Howrigan, D. P., M. A. Simonson, and M. C. Keller. 2011. Detecting autozygosity through runs of homozygosity: A comparison of three autozygosity detection algorithms. BMC Genomics 12:460 https:// doi.org/10.1186/1471-2164-12-460.
Javaher, P., M. Stuhrmann, C. Wilke, E. Frenzel, G. Manukjan, A. Grosshenig, F. Dechend, E. Schwaab, J. Schmidtke, and S. Schubert. 2012. Should TSPYL1 mutation screening be included in routine diagnostics of male idiopathic infertility? Fertil. Steril. 97:402-406. https://doi.org/10.1016/j.fertnstert.2011.11.002.

Keller, M. C., M. A. Simonson, S. Ripke, B. M. Neale, P. V. Gejman, D. P. Howrigan, S. H. Lee, T. Lencz, D. F. Levinson, and P. F. Sullivan. 2012. Runs of homozygosity implicate autozygosity as a schizophrenia risk factor. PLoS Genet. 8:e1002656. https://doi. org/10.1371/journal.pgen.1002656.

Kim, E. S., J. B. Cole, H. Huson, G. R. Wiggans, C. P. Van Tassel, B. A. Crooker, G. Liu, Y. Da, and T. S. Sonstegard. 2013. Effect of artificial selection on runs of homozygosity in U.S. Holstein cattle. PLoS One 8:e80813. https://doi.org/10.1371/journal. pone.0080813.

Kim, E. S., T. S. Sonstegard, C. P. Van Tassell, G. Wiggans, and M. F. Rothschild. 2015. The relationship between runs of homozygosity and inbreeding in Jersey cattle under selection. PLoS One 10:e0129967. https://doi.org/10.1371/journal.pone.0129967.

Kristensen, T., and A. Sorensen. 2005. Inbreeding-Lessons from animal breeding, evolutionary biology and conservation genetics. Anim. Sci. 80:121-133.

Leroy, G. 2014. Inbreeding depression in livestock species: Review and meta-analysis. Anim. Genet. 45: https://doi.org/10.1111/ age. 12178.

Margulis, S. W., and A. Walsh. 2002. The effects of inbreeding on testicular sperm concentration in Peromyscus polionotus. Reprod. Fertil. Dev. 14:63-67. https://doi.org/10.1071/RD01120.

Maximini, L., B. Fuerst-Waltl, B. Gredler, and R. Baumung. 2011. Inbreeding depression on semen quality in Austrian dual-purpose Simmental bulls. Reprod. Domest. Anim. 46:e102-e104. https:// doi.org/10.1111/j.1439-0531.2010.01645.x.

McQuillan, R., A. L. Leutenegger, R. Abdel-Rahman, C. S. Franklin, M. Pericic, L. Barac-Lauc, N. Smolej-Narancic, B. Janicijevic, O. Polasek, A. Tenesa, A. K. MacLeod, S. M. Farrington, P. Rudan, C. Hayward, V. Vitart, I. Rudan, S. H. Wild, M. G. Dunlop, A. F. Wright, H. Campbell, and J. F. Wilson. 2008. Runs of homozygosity in European populations. Am. J. Hum. Genet. 83:359-372. https://doi.org/10.1016/j.ajhg.2008.08.007.

Musset, B., R. A. Clark, T. E. DeCoursey, G. L. Petheo, M. Geiszt, Y. Chen, J. E. Cornell, C. A. Eddy, R. G. Brzyski, and A. El Jamali. 2012. NOX5 in human spermatozoa: Expression, function, and regulation. J. Biol. Chem. 287:9376-9388. https://doi.org/10.1074/ jbc.M111.314955.

Oliehoek, P. A., J. J. Windig, J. A. M. Van Arendonk, and P. Bijma. 2006. Estimating relatedness between individuals in general populations with a focus on their use in conservation programs. Genetics 173:483-496. https://doi.org/10.1534/genetics.105.049940.

Pacheco, S. E., E. A. Houseman, B. C. Christensen, C. J. Marsit, K. T. Kelsey, M. Sigman, and K. Boekelheide. 2011. Integrative DNA methylation and gene expression analyses identify DNA packaging and epigenetic regulatory genes associated with low motility sperm. PLoS One 6:e20280. https://doi.org/10.1371/journal. pone.0020280.

Palmieri, F. 2013. The mitochondrial transporter family SLC25: Identification, properties and physiopathology. Mol. Aspects Med. 34:465-484. https://doi.org/10.1016/j.mam.2012.05.005.

Pausch, H., S. Kölle, C. Wurmser, H. Schwarzenbacher, R. Emmerling, S. Jansen, M. Trottmann, C. Fuerst, K. U. Götz, and R. Fries. 2014. A nonsense mutation in TMEM95 encoding a nondescript transmembrane protein causes idiopathic male subfertility in cattle. PLoS Genet. 10:e1004044. https://doi.org/10.1371/journal. pgen.1004044.

Pausch, H., H. Schwarzenbacher, J. Burgstaller, K. Flisikowski, C. Wurmser, S. Jansen, S. Jung, A. Schnieke, T. Wittek, and R. Fries. 2015. Homozygous haplotype deficiency reveals deleterious mutations compromising reproductive and rearing success in cattle. BMC Genomics 16:312. https://doi.org/10.1186/s12864-015-14837.

Pryce, J. E., M. Haile-Mariam, M. E. Goddard, and B. J. Hayes. 2014. Identification of genomic regions associated with inbreeding 
depression in Holstein and Jersey dairy cattle. Genet. Sel. Evol. 46:71. https://doi.org/10.1186/s12711-014-0071-7.

Pukazhenthi, B. S., K. Neubauer, K. Jewgenow, J. Howard, and D. E. Wildt. 2006. The impact and potential etiology of teratospermia in the domestic cat and its wild relatives. Theriogenology 66:112-121. https://doi.org/10.1016/j.theriogenology.2006.03.020.

Purfield, D. C., D. P. Berry, S. McParland, and D. G. Bradley. 2012. Runs of homozygosity and population history in cattle. BMC Genet. 13:70. https://doi.org/10.1186/1471-2156-13-70.

Ruiz-Lopez, M. J., D. P. Evenson, G. Espeso, M. Gomendio, and E. R. S. Roldan. 2010. High levels of DNA fragmentation in spermatozoa are associated with inbreeding and poor sperm quality in endangered ungulates. Biol. Reprod. 83:332-338. https://doi. org/10.1095/biolreprod.110.084798

Sabeur, K., and B. A. Ball. 2007. Characterization of NADPH oxidase 5 in equine testis and spermatozoa. Reproduction 134:263-270. https://doi.org/10.1530/REP-06-0120.

Sargolzaei, M., H. Iwaisaki, and J. J. Colleau. 2006. CFC: A tool for monitoring genetic diversity. (CD-ROM Communication, pages 27-28) in Proc. 8th World Congr. Genet. Appl. Livest. Prod.

Saura, M., A. Fernández, L. Varona, A. I. Fernández, M. Á. R. de Cara, C. Barragán, and B. Villanueva. 2015. Detecting inbreeding depression for reproductive traits in Iberian pigs using genomewide data. Genet. Sel. Evol. 47:1. https://doi.org/10.1186/s12711014-0081-5.

Schreiber, M., A. Wei, A. Yuan, J. Gaut, M. Saito, and L. Salkoff. 1998. Slo3, a novel $\mathrm{pH}$-sensitive $\mathrm{K}+$ channel from mammalian spermatocytes. J. Biol. Chem. 273:3509-3516. https://doi. org/10.1074/jbc.273.6.3509.

Shivaji, S., D. Jayaprakash, and S. B. Patil. 1998. Assessment of inbreeding depression in big cats: Testosterone levels and semen analysis. Curr. Sci. 75:923-930.

Shojaei Saadi, H. A., E. van Riemsdijk, A. L. Dance, G. D. Rajamanickam, J. P. Kastelic, and J. C. Thundathil. 2013. Proteins associated with critical sperm functions and sperm head shape are differentially expressed in morphologically abnormal bovine sperm induced by scrotal insulation. J. Proteomics 82:64-80. https://doi. org/10.1016/j.jprot.2013.02.027.

Soggiu, A., C. Piras, H. A. Hussein, M. De Canio, A. Gaviraghi, A. Galli, A. Urbani, L. Bonizzi, and P. Roncada. 2013. Unravelling the bull fertility proteome. Mol. Biosyst. 9:1188-1195. https://doi. org/10.1039/c3mb25494a.
Sölkner, J., M. Ferencakovic, B. Gredler, and I. Curik. 2010. Genomic metrics of individual autozygosity, applied to a cattle population. Page 306 in 61st Annual Meeting of the European Association of Animal Production, Heraklion. Wageningen Academic Publishers, Wageningen, the Netherlands.

Sonstegard, T. S., J. B. Cole, P. M. VanRaden, C. P. van Tassell, D. J. Null, S. G. Schroeder, D. Bickhart, and M. C. McClure. 2013. Identification of a nonsense mutation in CWC15 associated with decreased reproductive efficiency in Jersey cattle. PLoS One 8:e54872. https://doi.org/10.1371/journal.pone.0054872.

Uechi, T., N. Maeda, T. Tanaka, and N. Kenmochi. 2002. Functional second genes generated by retrotransposition of the X-linked ribosomal protein genes. Nucleic Acids Res. 30:5369-5375. https://doi. org/10.1093/nar/gkf696

van Eldik, P., E. H. Van Der Waaij, B. Ducro, A. W. Kooper, T. A. E. Stout, and B. Colenbrander. 2006. Possible negative effects of inbreeding on semen quality in Shetland pony stallions. Theriogenology 65:1159-1170. https://doi.org/10.1016/j. theriogenology.2005.08.001.

VanRaden. P. M. 2008. Efficient methods to compute genomic predictions. J. Dairy Sci. 91:4414-4423. http://dx.doi.org/https://doi. org $/ 10.3168 /$ jds.2007-0980.

Vernocchi, V., M. G. Morselli, S. Varesi, S. Nonnis, E. Maffioli, A. Negri, G. Tedeschi, and G. C. Luvoni. 2014. Sperm ubiquitination in epididymal feline semen. Theriogenology 82:636-642. https:/ doi.org/10.1016/j.theriogenology.2014.06.002.

Wang, X., N. Desai, Y. P. Hu, S. M. Price, C. Abate-Shen, and M. M. Shen. 2008. Mouse Fem1b interacts with the Nkx3.1 homeoprotein and is required for proper male secondary sexual development. Dev. Dyn. 237:2963-2972. https://doi.org/10.1002/dvdy.21694.

Wildt, D. E., E. J. Baas, P. K. Chakraborty, T. L. Wolfle, and A. P. Stewart. 1982. Influence of inbreeding on reproductive performance, ejaculate quality and testicular volume in the dog. Theriogenology 17:445-452. https://doi.org/10.1016/0093-691X(82)90026-7.

Wolkowicz, M. J., L. Digilio, K. Klotz, J. Shetty, C. J. Flickinger, and J. C. Herr. 2008. Equatorial segment protein (ESP) is a human alloantigen involved in sperm-egg binding and fusion. J. Androl. 29:272-282. https://doi.org/10.2164/jandrol.106.000604.

Yin, L. L., J. M. Li, Z. M. Zhou, and J. H. Sha. 2005. Identification of a novel testis-specific gene and its potential roles in testis development/spermatogenesis. Asian J. Androl. 7:127-137. https://doi. org/10.1111/j.1745-7262.2005.00041.x. 